\title{
Particle Size and Hydraulic Properties of Pumice Affect Growth and Yield of Greenhouse Crops in Soilless Culture
}

\author{
George Gizas \\ Faculty of Agricultural Technology, T.E.I. of Epirus, P.O. Box 110, 47100 \\ Arta, Greece \\ Dimitrios Savvas ${ }^{1}$ \\ Agricultural University of Athens, Laboratory of Vegetable Production, Iera \\ Odos 75, 11855 Athens, Greece
}

Additional index words. growing media, substrate, moisture retention curve, cucumber, gypsophila, rose, lettuce

Abstract. Four successive trials with gypsophila, rose, cucumber, and lettuce grown on different pumice grades were conducted in a heated glasshouse. In the gypsophila experiment, three grades of pumice ( 0 to 2,0 to 5 , and 0 to $8 \mathrm{~mm}$ ) were tested, whereas in the rose, cucumber, and lettuce experiments, four pumice grades (0 to 2,0 to 5,0 to 8 , and 4 to $8 \mathrm{~mm}$ ) were compared. In each experiment, these pumice grades were combined with two growing systems, specifically placement of the same media volume either in pots or in bags. Furthermore, the physical properties of the tested pumice grades were determined. Overall, gypsophila and cucumber gave the highest yields when grown in pots filled with the two finest pumice grades, whereas the yield obtained from plants grown in bags was poor regardless of particle size range. Coarse pumice restricted gypsophyla and cucumber yield in pot culture to nearly the same degree as in bags. In contrast, lettuce, and to a greater degree roses, exhibited a weaker response to the different pumice grades and growing systems. The two finer pumice grades were characterized by relatively low air-filled porosity, which presumably restricted plant growth and yield as a result of poor root aeration when the media were placed in bags with a height of $8 \mathrm{~cm}$. The coarsest pumice grades were characterized by a steep drop in the water content as the suction increased only a few centimeters above zero, which imposed an appreciable lowering of the overall water content in the pots in comparison with the bags $(\approx 12.5 \%)$, as a result of the increased height of the former. Our results indicate that gypsophila and cucumber respond more strongly than roses and lettuce to the variations in the air-to-water ratio in the root zone originating from differences in the physical properties of the growing media.

Most growers prefer to grow greenhouse plants in porous substrates rather than in pure nutrient solution, because the former provide better root aeration and a higher buffering capacity (Van Os et al., 2002). However, both root aeration and water availability in the rhizosphere strongly depend on the physical properties of the substrates, which in turn are conditioned by the shape and size of their constituent particles (Da Silva et al., 1993; Hanan et al., 1981; Raviv et al., 2002). Given that the commonly used substrates are either natural or industrially processed materials originating from natural resources, the size of their particles may vary within a wide

Received for publication 19 Jan. 2007. Accepted for publication 14 Mar. 2007.

This investigation formed part of a research project of the Research Committee of TEI of Epirus funded by LAVA S.A.

We thank Miss E. Stamou and Mr. A. Antoniou for excellent technical assistance and Prof. HaroldChristopher Passam from the Agricultural University of Athens for reviewing the manuscript.

${ }^{1}$ To whom reprint requests should be addressed; e-maildsavvas@aua.gr range. Therefore, the particle size of a particular substrate is commonly described as a fractional distribution of size ranges (Wallach et al., 1992).

Pumice is an inert aluminosilicate mineral of volcanic origin characterized by high porosity and, therefore, by low density (Boertje, 1995; Challinor, 1996). For use as a horticultural substrate, pumice blocks are ground into small particles that range from a fine dust to $8 \mathrm{~mm}$. Pumice is free of pathogens and weed seeds, has a very low ion exchange capacity, and a stable structure, whereas its disposal, given its natural origin, does not pollute the environment (Raviv et al., 2002). Furthermore, in countries where pumice is produced locally, it is available at fairly low prices as a result of the minimal industrial processing required to prepare the granulated form used in horticulture (Gunnlaugsson and Adelsteinsson, 1995; Maloupa, 2002), thus further encouraging its adoption as a soilless substrate (Maloupa et al., 2001). Despite these advantages, information on the responses of plants to the physical and chemical properties of pumice, as well as the method of cultivation on this substrate (e.g., cultivation in bags or containers), is currently limited (Challinor, 1996; Gunnlaugsson and Adelsteinsson, 1995; Raviv et al., 2002). Raviv et al. (1999) compared the performance of rose (Rosa $\times$ hybrida) on pumice from two sources (Greece and Italy) with tuff, a pyroclastic volcanic material that is widely used as horticultural substrate in Israel. The results indicated that both types of pumice were inferior to tuff as a result of limitations in water availability. However, the types of pumice used by Raviv et al. (1999) consisted of over 90\% (wt. basis) in the one instance and $65 \%$ in the other of coarse particles with a size exceeding 4.75 $\mathrm{mm}$. In contrast, finer particles with a smaller size than $1.7 \mathrm{~mm}$ constituted less than $5 \%$ and $15 \%$ of the pumice weight, respectively. Coarse pumice (known as "pumice 5-8 $\mathrm{mm}$ grade") has an unbalanced particle size distribution and is only exceptionally used for plant growth, whereas particle sizes ranging from 0 to 5 or 0 to $8 \mathrm{~mm}$ are normally used in soilless culture. Fine particles are generally associated with small pores and thus have a high water-holding capacity and media hydraulic conductivity (Drsal et al., 1999; Raviv et al., 2002). On the other hand, coarse particles form larger pores, which favor root aeration (Raviv et al., 2002). Hence, to evaluate pumice as a plant substrate, it is essential to compare particles differing in size range and distribution. Furthermore, the actual container capacity of a containerized substrate, and thus the air-filled porosity and the water-holding capacity, depend on container height (Fonteno, 1996; Milks et al., 1989b). Hence, the container used to accommodate the substrate, which determines the three-dimentional distribution of the substrate volume, may also considerably influence plant performance.

In view of the above considerations, the present study was aimed at comparing the performance of four representative greenhouse crops (rose, gypsophila, cucumber, and lettuce) on four types of pumice differing in particle size ( 0 to 2,0 to 5,0 to 8 , and 4 to $8 \mathrm{~mm}$ ) placed either in bags or in pots. To assess the growth and yield performance in each treatment, the particle size distribution and the moisture retention curve for each grade of pumice were also determined.

\section{Materials and Methods}

Physical characteristics of the substrate

The particle size distribution of the four pumice grades tested in these experiments was determined using sieves with meshes corresponding to the specifications (C 13606) of the American Society for Testing and Materials. Furthermore, the effective pore space (volumetric percentage of pore space that can be actually filled with water, which was defined by measuring the volumetric water content at saturation), the air-filled porosity (AFP: volumetric air content at $10 \mathrm{~cm}$ water suction), the easily available water (EAW: difference of volumetric water content between 10 and $50 \mathrm{~cm}$ water suction), the 
water buffering capacity (WBC: difference of volumetric water content between 50 and $100 \mathrm{~cm}$ water suction), and the moisture retention curve of each pumice type were determined using a sandbox apparatus (Eijkelkamp, Giesbeek, The Netherlands). The definitions for these physical characteristics are those suggested by Bunt (1988). To determine these physical characteristics of the four different types of pumice, 16 samples (four samples per pumice grade) were placed in $100-\mathrm{cm}^{3}$ rings to the bottom of which a piece of ultrathin capillary material, supplied by the manufacturer of the sandbox, had been fixed to facilitate their subsequent removal without loss of pumice material. The samples were saturated with distilled water by setting in $1 \mathrm{~cm}$ water in the sandbox, waiting for $1 \mathrm{~h}$, and then slowly raising the water level to the top of the ring for a period of $5 \mathrm{~d}$. After saturation had been established, the samples were subjected to a water suction of $100 \mathrm{~cm}$ to precisely tune their volume to $100 \mathrm{~cm}^{3}$ and then resaturated with water like in the initial saturation process. Thereafter, their moisture content was gradually balanced to increasing values of suction in the range from 0 to 100 $\mathrm{cm}$. To ensure establishment of steady moisture conditions in the bulk of the samples at each suction level, the time intervals between each step of suction increase were at least $6 \mathrm{~d}$. After the establishment of moisture equilibrium at each suction level, the samples were removed from the sandbox by means of a sharp slice, weighed, and then returned back to their position. Finally, the pumice samples were oven-dried and weighed to determine their bulk density (BD). The moisture retention curves of the four pumice types are illustrated by graphically presenting both the means of four measured values at each suction level and the corresponding best fit curves. The latter were established by using a model proposed by Van Genuchten (1980) and Van Genuchten and Nielson (1985) for soils and adapted to horticultural substrates by Milks et al. (1989a):

$$
S_{e}=\left[1+(a h)^{n}\right]^{-m}
$$

where $h$ is the water suction in centimeters of water, $a$ and $n$ are parameters depending on the physical characteristics of the substrate, which have to be determined empirically by nonlinear regression analysis, $m=1-1 / n$, and $S_{e}$ is the effective saturation, which, by definition, is given by equation:

$$
S_{e}=\left(\theta-\theta_{r}\right) /\left(\theta_{s}-\theta_{r}\right)
$$

In Eq. (2), $\theta$ depicts the volumetric moisture content of the substrate and the subscripts $s$ and $r$ refer to the saturated and residual moisture content, respectively. Substituting (2) in (1) one results in:

$$
\theta=\theta_{r}+\left(\theta_{s}-\theta_{r}\right) /\left[1+(a h)^{n}\right]^{m}
$$

As previously mentioned, $\theta_{s}$ was measured, whereas $\theta_{r}$ was determined empirically as the water content at which the gradient $d \theta / d h$ became zero (Raviv et al., 2002). Eq. (3) was used to graphically illus- trate the relationship between moisture tension $(h)$ and moisture content $(\theta)$ for each grade of pumice. Furthermore, Eq. (3) was used to calculate the actual water content (AWC) of each pumice grade at container capacity, which corresponded to the container heights involved in the present experiments (see subsequently). This was attained by integrating (3) within the range from 0 to the actual height of each container (pot or bag) and dividing by the container height. In addition, the actual air content (AAC) of each of the containers at container capacity was calculated by subtracting the AWC from the total porosity for each pumice grade.

\section{Experimental setup and cultural practices}

Four successive trials with gypsophila, rose, cucumber, and lettuce were conducted in a heated, fully automated glasshouse located in Arta (lat. $39^{\circ} 7^{\prime} \mathrm{N}$, long. $20^{\circ} 56^{\prime} \mathrm{E}$ ), Greece. All crops were grown in a fully automated hydroponic installation consisting of 24 channels, $5 \mathrm{~m}$ in length and $0.25 \mathrm{~m}$ in breadth, which corresponded to 24 experimental units. In all experiments, the plants were planted either in cylindrical pots or in opaque, polyethylene bags, which were filled with pumice. In the gypsophila experiment, three types of pumice ( 0 to 2, 0 to 5 , and 0 to $8 \mathrm{~mm}$ ) were tested, which together with the two different cultivation methods (placement in bags or in pots) resulted in a two-factorial, completely randomized experimental design with six treatments and four replications. In the experiments with rose, cucumber, and lettuce, four pumice grades ( 0 to 2, 0 to 5,0 to 8 , and 4 to $8 \mathrm{~mm}$ ) were tested in bags or pots, resulting in eight different treatments with three replications per treatment. The particle size ranges are nominal, because the tested pumice types are commercial grades commonly offered in the market. The pots were perforated at the base to allow free drainage, whereas a piece of net placed within prevented the leaching of pumice particles. To allow free drainage in the bags, a slit was made in the base of each at a point equidistant between two successive plants.

Nutrient solution was automatically prepared and supplied to the plants by means of a computer-controlled installation and a drip irrigation system. All channels were covered with black-white polyethylene sheets to minimize water evaporation. In all experimental units, the drainage water was captured and recycled after replenishment with fresh nutrient solution and nitric acid to adjust the $\mathrm{pH}$ according to the method of reference nutrient solution proposed by Savvas and Manos (1999) and Savvas (2001). This method is based on the supply of nutrients to a closed hydroponic system to compensate for plant uptake at constant ratios but varying the absolute doses according to the online measured volume and electrical conductivity of the recycled drainage solution. The nutrient ratios in both the standard nutrient solution and the reference nutrient solution, which was used after recycling initiation to replen- ish plant uptake, were as suggested by De Kreij et al. (1999) for closed systems. The $\mathrm{pH}$ of the nutrient solution supplied to the plants was automatically adjusted to 5.7 in the gypsophila and 5.6 in the rose, cucumber, and lettuce experiments using nitric acid. Irrigation was automatically controlled by relating the frequency of the nutrient solution supply to the solar radiation intensity, which was continuously monitored by means of a pyranometer. In each experiment, the integral of the solar radiation intensity at which an irrigation event was triggered was identical in all treatments, aiming at a target drainage percentage of $40 \%$ to $50 \%$, but varied during the cropping period according to plant size. Excessively high summer temperatures were controlled by passive ventilation and shading screens.

The data were subjected to factorial analyses of variance (pumice grade $\times$ container type) by using the PlotIT3.2 (Scientific Programming Enterprises, Haslett, MI) work package, which was also used for the graphical representation of the results. When a significant interaction between the two experimental factors was obtained, all possible comparisons between the treatments were carried out by using Duncan's multiple range test. The specific cultural conditions and experimental procedures applied in each experiment are outlined subsequently.

Gypsophila. Rooted cuttings of gypsophila (Gypsophila paniculata, cv. Perfecta) were planted on 6 Dec. 2002. Each experimental unit (channel) accommodated 15 gypsophila plants placed at intervals of 33.3 $\mathrm{cm}$. One gypsophila plant was planted in each pot, which had a height of $17 \mathrm{~cm}$ (container height) and an effective volume of $4 \mathrm{~L}$. Each bag had a length of $100 \mathrm{~cm}$, a height of $8 \mathrm{~cm}$ (container height), and an effective volume of $12 \mathrm{~L}$ and accommodated three plants. Thus, the volume of pumice per plant was $4 \mathrm{~L}$ in both cases. The plant density was 1.8 plants per meter squared.

Flower induction was initiated by means of supplementary lighting (15-d photoperiod) using incandescence lamps. Harvesting of commercially acceptable flowers $(50 \%$ of flowers opened) began on 18 Apr. 2003 and was ended on 15 May 2003. At each harvest date, the fresh weight of the flowers collected in each channel (experimental unit) was determined separately. At the end of the experiment, the roots and the vegetative shoot of two randomly selected plants per channel were weighed to determine the treatment impact on growth.

Rose. Rooted rose cuttings (Rosa $\times$ hybrida, cv. First red) were planted on 16 June 2003. Each experimental unit (channel) accommodated 36 plants. Each pot, which was $24 \mathrm{~cm}$ in height (container height) and top diameter, was filled with pumice up to a volume of $8 \mathrm{~L}$ and accommodated two rose plants. Each bag, which had a length of 125 $\mathrm{cm}$, a breadth of $24 \mathrm{~cm}$, and a height of $12 \mathrm{~cm}$ (container height) corresponding to $36 \mathrm{~L}$ of pumice, accommodated nine rose plants. Thus, the volume of substrate per plant was $4 \mathrm{~L}$ in all treatments. During the cropping 
period, the plants were regularly pruned by pinching and bending down all weak stems to maximize the photosynthetic leaf area. Harvesting of rose flowers started on 1 Sept. 2003 and lasted until 8 July 2004, when the experiment was ended. During the entire growing period, the harvested flowers from all treatments and all plants of each treatment were counted, weighed, and graded and their length recorded.

Cucumber. Cucumber (Cucumis sativus L., cv. Galileo F1, Sakata) seedlings grown in peat cubes $(4 \times 4 \times 4 \mathrm{~cm})$ were transferred to pumice as soon as the third true leaf had expanded. An effective length of $4 \mathrm{~m}$ was used in each channel by placing eight plants at intervals of $0.5 \mathrm{~m}$ along it. The pots were identical with those used for gypsophila (container height $17 \mathrm{~cm}$ ) and each accommodated one plant. Each bag, which had a length of $100 \mathrm{~cm}$, a breadth of $10 \mathrm{~cm}$, and a height of $8 \mathrm{~cm}$ (container height), corresponding to an effective substrate volume of $8 \mathrm{~L}$, accommodated two plants. Thus, the volume of pumice per plant was $4 \mathrm{~L}$ in all treatments. This planting arrangement resulted in a crop density of 1.2 plants per meter squared. The plants were pruned according to the umbrella training system (Klieber et al., 1993). The cucumber seedlings were planted on 19 Nov. 2004. Harvesting of commercially ripe fruits began on 28 Dec. 2004 and was ended on 8 Apr. 2005. Harvesting was performed twice per week throughout the cropping period. At each harvest, the fruit weight, total number of harvested fruits, and fruit length were recorded separately for each experimental unit.

Lettuce. Seedlings of lettuce (Lactuca sativa L., cv. Vardac) were planted in pumice at the stage of three true leaves on 17 Apr. 2005. An effective length of $2 \mathrm{~m}$ was used in each channel by placing eight plants at intervals of $0.25 \mathrm{~m}$ along it. This planting arrangement resulted in a crop density of 2.4 plants per meter squared. The pots were identical to those used for gypsophila and cucumber (container height $17 \mathrm{~cm}$ ) and each accommodated one plant. Each bag, which had a length of $100 \mathrm{~cm}$, a width of $20 \mathrm{~cm}$, and a height of $8 \mathrm{~cm}$ (container height), corresponding to an effective volume of $16 \mathrm{~L}$, accommodated four plants. Thus, the volume of pumice per plant was $4 \mathrm{~L}$ in all treatments. The lettuce plants were harvested on 24 May 2005, when they reached commercial maturity (complete head formation) following the common growing practice for the particular cultivar. At crop termination, all the plants from each channel were harvested and their weight recorded individually. The plants collected from each channel were used to calculate a mean fresh weight per plant and thus for each treatment, a mean of three measured values was computed.

\section{Results}

Physical properties. The distribution of the pumice particles in size ranges (Fig. 1) revealed that the differences between grades
0 to 2 and 0 to $5 \mathrm{~mm}$ are comparably small, although the 0 - to 2-mm grade has a larger percentage of fine particles (less than 0.6 $\mathrm{mm})$ and a correspondingly smaller fraction of coarser particles ( 2.39 to $4 \mathrm{~mm}$ ). It is noted that $\approx 10 \%(\mathrm{w} / \mathrm{w})$ of the coarsest pumice grade (4 to $8 \mathrm{~mm}$ ) consisted of fine particles (less than $0.6 \mathrm{~mm}$ ). Similarly, more than $5 \%$ $(\mathrm{w} / \mathrm{w})$ of the pumice type offered as 0- to 2$\mathrm{mm}$ grade in the market had a larger size than $2.38 \mathrm{~mm}$.

The BD of the tested pumice grades increased with decreasing particle size, whereas the AFP decreased (Table 1). The effective pore space did not follow a consistent change as the particle size range of pumice increased from 0 to 2 to 0 to $8 \mathrm{~mm}$ but was markedly higher in the coarsest grade ( 4 to $8 \mathrm{~mm}$ ). The finer grades of pumice ( 0 to 2 and 0 to $5 \mathrm{~mm}$ ) contained a higher percentage $(7.14 \%$ and $8.23 \%$, respectively) of EAW in comparison with 0 to $8 \mathrm{~mm}(4.76 \%)$, whereas the EAW in the coarsest type (4 to
$8 \mathrm{~mm}$ ) amounted to only $1.07 \%$. Compared with EAW, the WBC exhibited a similar but more consistent increase as the particle size of pumice decreased.

A comprehensive view regarding the changes in the volumetric water content of the four types of pumice as the matrix potential of the substrate decreased (increasing suction) was provided by the corresponding water retention curves in Figure 2. Overall, the measured values were in good agreement with the curves fitted by means of nonlinear regression analysis using Eq. (1) as a model. All types of pumice were characterized by a rapid decrease of the volumetric water content as the suction increased, but this phenomenon was much more marked in the coarsest grade ( 4 to $8 \mathrm{~mm}$ ). Furthermore, the residual moisture content tended to be higher with finer pumice grades.

The AWC of pumice at container capacity decreased with increasing container height, whereas the AAC rose (Table 2). Overall, the
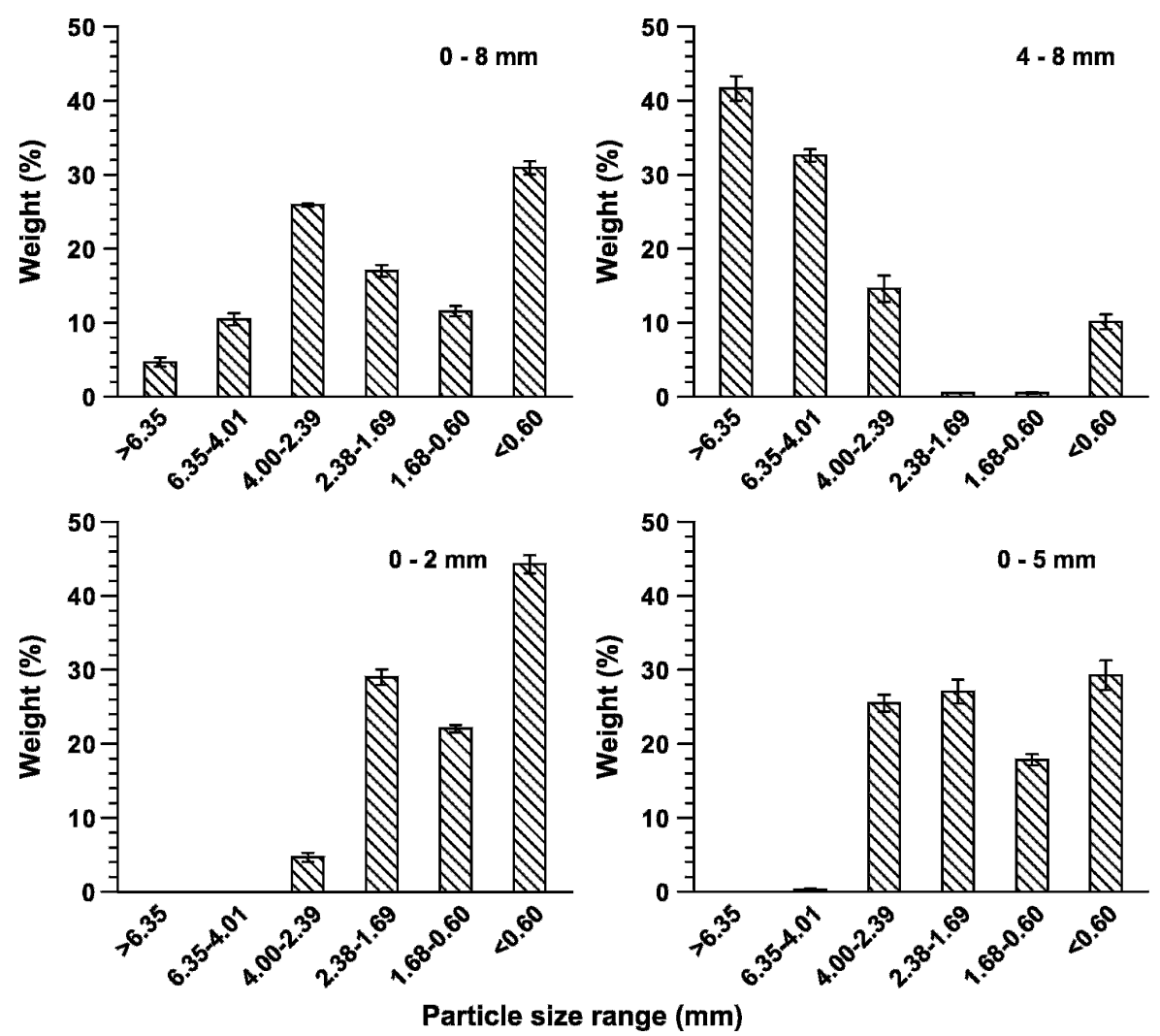

Fig. 1. Particle size distribution of four types of pumice differing in particle size range. Vertical bars indicate $\pm \mathrm{SE}$ of means calculated from four measurements.

Table 1. Bulk density (BD), effective pore space (EPS), air-filled porosity (AFP), easily available water (EAW), and water-buffering capacity (WBC) of four types of pumice differing in particle size range. ${ }^{\mathrm{z}}$

\begin{tabular}{lccccc}
\hline $\begin{array}{l}\text { Particle size } \\
\text { range }(\mathrm{mm})\end{array}$ & $\mathrm{BD}\left(\mathrm{g} \cdot \mathrm{cm}^{-3}\right)$ & EPS $(\% \mathrm{v} / \mathrm{v})$ & AFP $(\% \mathrm{v} / \mathrm{v})$ & EAW $(\% \mathrm{v} / \mathrm{v})$ & WBC $(\% \mathrm{v} / \mathrm{v})$ \\
\hline $0-2$ & $0.952 \mathrm{a}$ & $53.1 \mathrm{~b}$ & $13.5 \mathrm{c}$ & $7.14 \mathrm{~b}$ & $2.27 \mathrm{a}$ \\
$0-5$ & $0.938 \mathrm{~b}$ & $51.0 \mathrm{c}$ & $14.3 \mathrm{c}$ & $8.23 \mathrm{a}$ & $2.00 \mathrm{~b}$ \\
$0-8$ & $0.829 \mathrm{c}$ & $53.0 \mathrm{~b}$ & $19.7 \mathrm{~b}$ & $4.76 \mathrm{c}$ & $1.54 \mathrm{c}$ \\
$4-8$ & $0.620 \mathrm{~d}$ & $62.0 \mathrm{a}$ & $38.7 \mathrm{a}$ & $1.07 \mathrm{~d}$ & $0.57 \mathrm{~d}$ \\
\hline
\end{tabular}

${ }^{z}$ Values are means of four measurements. Mean separation in columns by Duncan's multiple range test. In each column, values followed by the same letter do not differ significantly at $P \leq 0.05$. 
finer pumice grades were associated with higher AWC and lower AAC levels at container capacity and vice versa. However, the percentages of AWC increase and AAC decrease with rising container height were similar in all pumice grades.

\section{Growth and yield responses}

The shoot fresh weight of gypsophila plants grown in bags was restricted in comparison with that of plants cultivated in pots, the difference being more profound as the particle size of pumice decreased (Fig. 3). The root and flower fresh weight per plant exhibited a similar response to the cultivation method (pot or bag) as that of the shoot, but the differences between bag and pot were insignificant when coarser particles of pumice $(0$ to $8 \mathrm{~mm})$ were used. When gypsophila was grown in pots, the use of finer pumice particles with a size ranging from 0 to $2 \mathrm{~mm}$ was favorable for both the vegetative growth and the flower yield. In contrast, the accom- modation of pumice in bags resulted in heavier gypsophila shoots when coarser particles $(0$ to $8 \mathrm{~mm})$ were used.

Unlike gypsophila, the flower yield of roses was not influenced by either of the media used to accommodate pumice or the particle size of the substrate, when the latter ranged from 0 to 2,0 to 5 , or 0 to $8 \mathrm{~mm}$ (Fig. 4). In the experiment with roses, these pumice grades were compared also with a very coarse type of pumice with a particle size ranging from 4 to $8 \mathrm{~mm}$. The results indicated that such a type of pumice may significantly restrict the total number of rose flowers per plant, particularly if the substrate is placed in pots.

In the cucumber experiment, a highly significant interaction, similar to that observed with gypsophila, was obtained between the particle size of pumice and the container used to accommodate the substrate with respect to the number and weight of fruits per plant (Fig. 5). In particular, both the

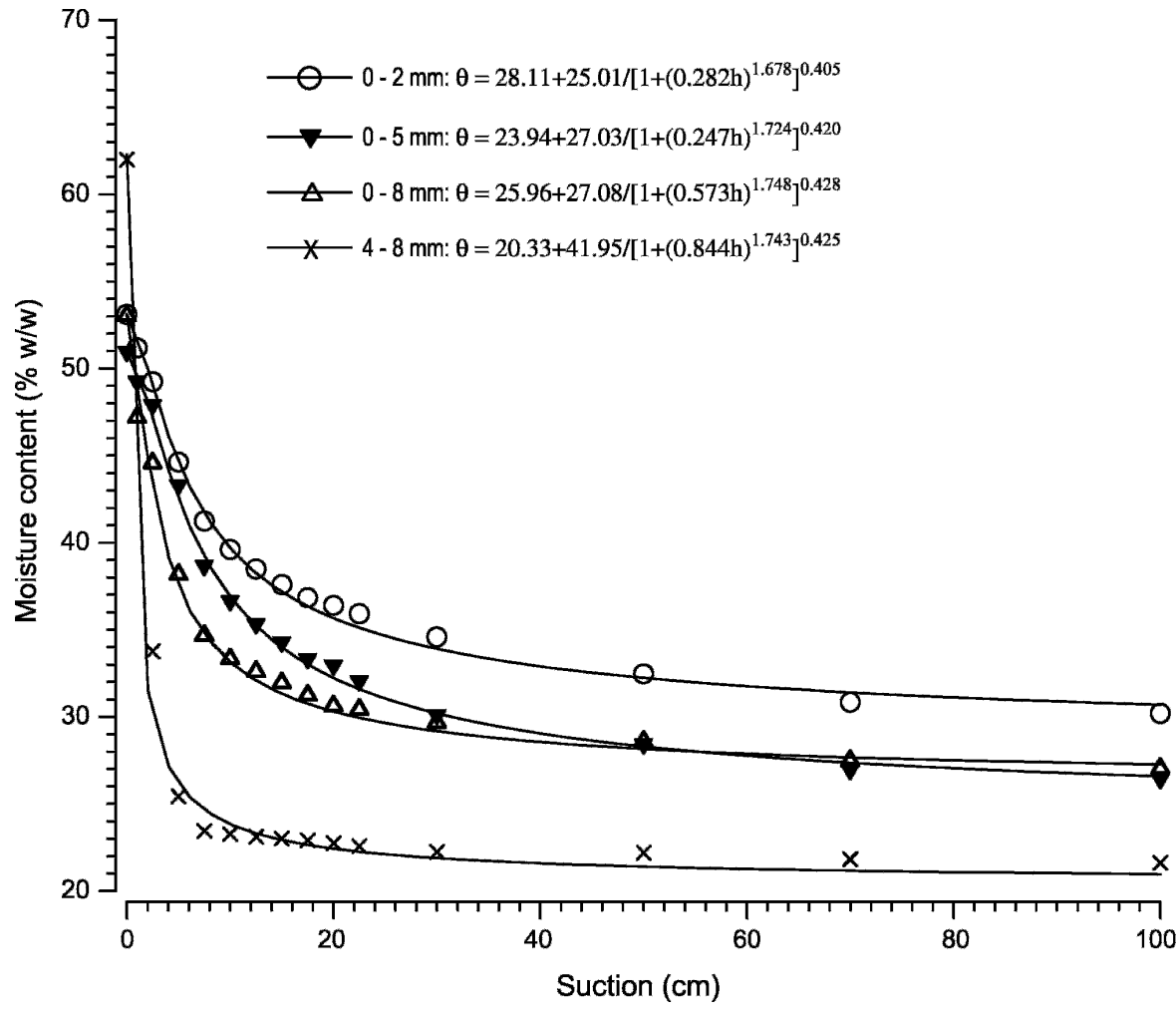

Fig. 2. Moisture retention curves (relationship between the moisture content and the suction exerted by the porous medium) of four pumice types differing in particle size range. Symbols indicate measured values, whereas curves indicate the values predicted by nonlinear regression analysis using Eq. (1) as a model number and the weight of cucumber fruits per plant were significantly restricted when coarse pumice (4 to $8 \mathrm{~mm}$ ) was used in place of the finer grades in pots. In contrast, when the substrate was placed in bags, the cultivation on the coarsest type of pumice tended to enhance the number and the weight of cucumber fruits per plant in comparison with those grown on finer particles, although the differences were not significant. The mean weight of cucumber fruit was not influenced either by the particle size of pumice or by the container used to accommodate the substrate. With respect to fruit length, the longest cucumbers were obtained from plants grown in pots filled with the 0 - to $2-\mathrm{mm}$ pumice grade, while the shortest fruits were harvested when pumice of the 4- to 8-mm type was placed in pots.

The highest fresh weight of lettuce foliage was obtained by placing pumice 0 to $5 \mathrm{~mm}$ in pots, but the difference was statistically significant only in comparison with pumice 0 to $2 \mathrm{~mm}$ placed in bags, pumice 0 to $8 \mathrm{~mm}$ placed in pots, or pumice 4 to $8 \mathrm{~mm}$ regardless of container type (Fig. 6). The growth of plants in coarse pumice (4 to $8 \mathrm{~mm}$ ) was better in bags than in pots but inferior to those grown in 0 to $5 \mathrm{~mm}$ pumice, irrespective of the container type, or fine ( 0 to $2 \mathrm{~mm}$ ) pumice in pots or 0 to $8 \mathrm{~mm}$ pumice in bags. The most profound suppression of the shoot fresh weight of lettuce was imposed by coarse pumice (4 to $8 \mathrm{~mm}$ ) placed in pots.

In all greenhouse experiments, the interaction between pumice grade and container type (pot or bag) was highly significant when the experimental factors had a significant effect on a particular measured parameter.

\section{Discussion}

Pumice is a chemically inactive porous medium irrespective of the size of its particles (Gizas et al., 1999), and all plants of each trial were supplied with nutrient solution of the same mineral composition at identical irrigation dosages. In addition, mineral analysis of young fully expanded leaves of gypsophila, the crop with the most marked growth and yield differences between the experimental treatments, revealed no differences in nutrient levels (data not shown). Hence, the yield differences between the treatments cannot be ascribed to variations in the supply of nutrients and presumably arise from the large differences in the physical properties of the tested pumice grades

Table 2. Estimated actual water content (AWC) and actual air content (AAC) at container capacity in relation to the height of the container and the particle size range of pumice.

\begin{tabular}{|c|c|c|c|c|c|c|c|c|}
\hline \multirow{2}{*}{$\begin{array}{l}\text { Particle size } \\
\text { range }(\mathrm{mm})\end{array}$} & \multicolumn{8}{|c|}{ Container $\mathrm{ht}(\mathrm{cm})$} \\
\hline & \multicolumn{2}{|c|}{8} & \multicolumn{2}{|c|}{12} & \multicolumn{2}{|c|}{17} & \multicolumn{2}{|c|}{24} \\
\hline $0-2$ & 46.8 & 6.3 & 44.4 & 8.7 & 42.4 & 10.7 & 40.4 & 12.7 \\
\hline $0-8$ & 41.1 & 12.0 & 38.4 & 14.6 & 36.4 & 16.7 & 34.5 & 18.5 \\
\hline $4-8$ & 30.6 & 31.4 & 28.3 & 33.6 & 26.8 & 35.2 & 25.5 & 36.5 \\
\hline
\end{tabular}

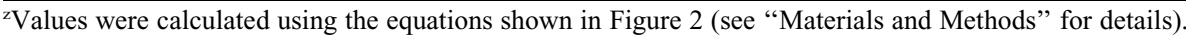



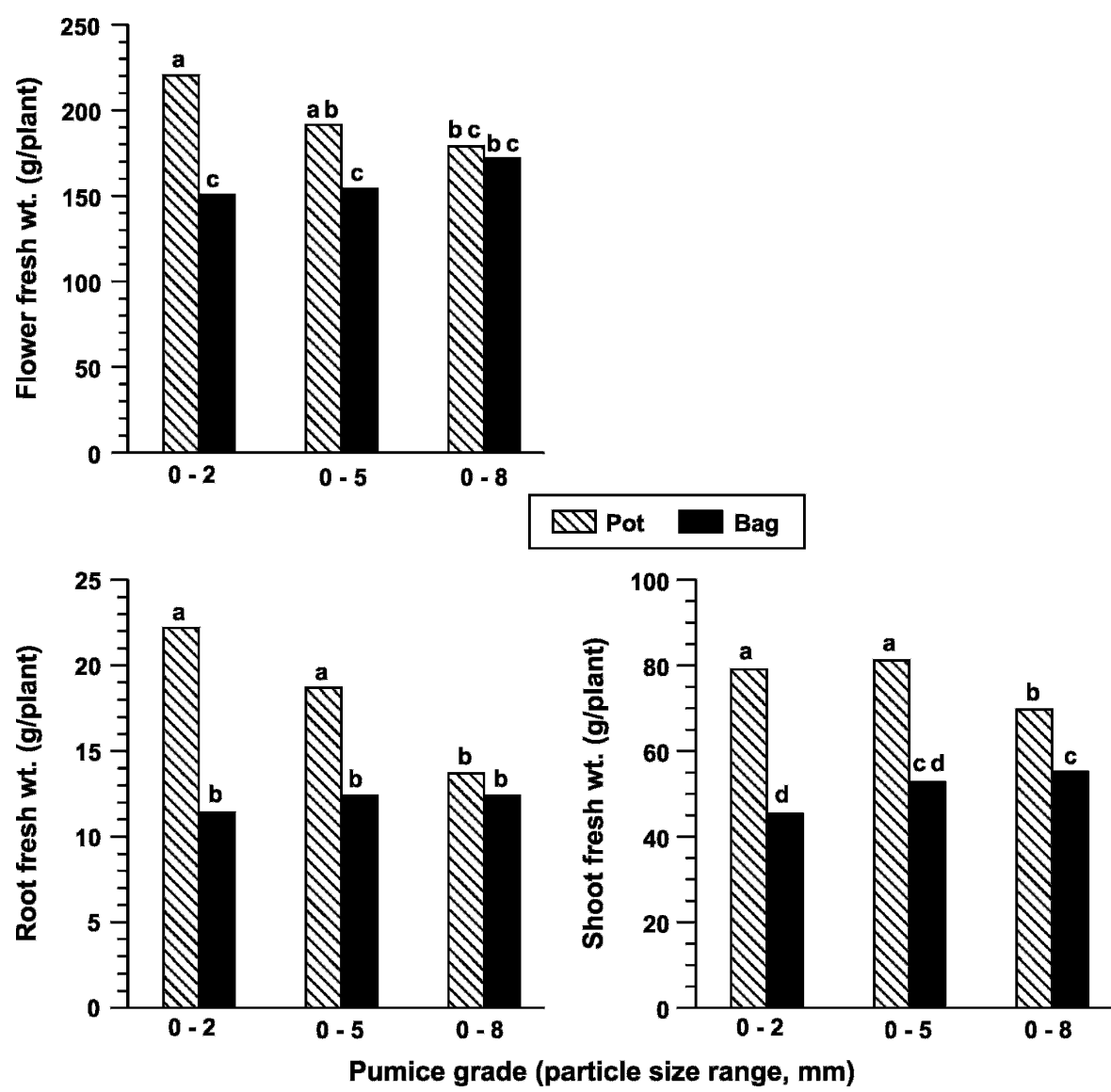

Fig. 3. Effects of particle size of pumice and cultivation method (placement of the growing media in pots or bags) on the vegetative growth and flower yield of gypsophila. Values are means of four measurements. In each graph, bars denoted by the same letter do not differ significantly at $P \leq 0.05$ according to Duncan's multiple range test.

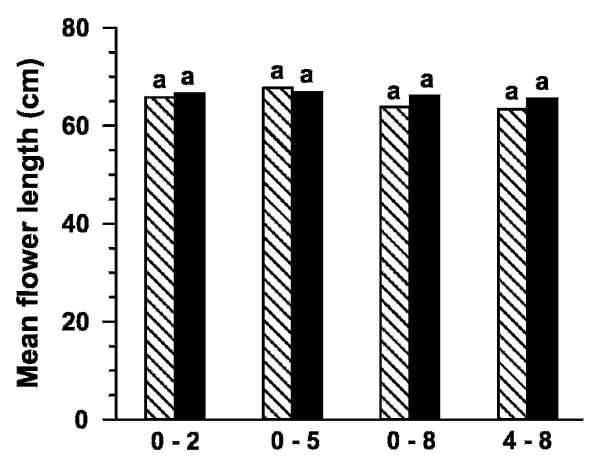

Dot Bag

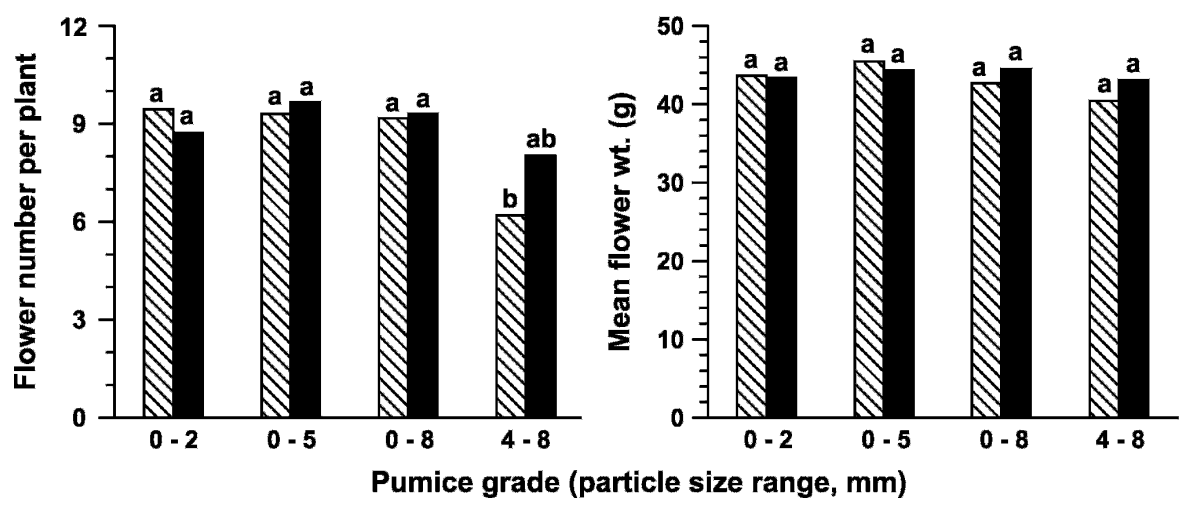

Fig. 4. Effects of particle size of pumice and cultivation method (placement of the growing media in pots or bags) on the total flower yield and flower size of roses. Values are means of three measurements. In each graph, bars denoted by the same letter do not differ significantly at $P \leq 0.05$ according to Duncan's multiple range test.
(Table 1), which are known to strongly affect the supply of air and water to the root system (Raviv et al., 2002). Thus, gypsophila, which performs poorly in soils with a high water table and requires well-drained rooting media for best production (Armitage, 1993), exhibited a profound reduction in growth and yield when grown on fine pumice grades placed in bags. The yield reduction observed in cucumber plants grown on fine pumice placed in bags seems to originate from limited root aeration too, given that cucumber is rather susceptible to low oxygen levels in the root zone (Gislerød and Kempton, 1983). As reported by Allaire et al. (1996), oxygen deficiency may readily occur in media with relatively low air-filled porosity, especially if the plants exhibit high growth rates, which demand intensive root respiration. As shown in Table 1, the air-filled porosity of the two finer pumice grades is relatively low (ranging from $13.5 \%$ to $14.3 \%$ ), and this is a disadvantage, especially for plants grown in bags, as a result of the low height of the latter $(8 \mathrm{~cm}$ in the gypsophila, cucumber, and lettuce crops). Indeed, as outlined by Milks et al. (1989b) and Fonteno (1996), as the height of medium increases, the force of gravity exerted in water increases too, thereby enhancing drainage of the water and improving the aeration of the medium at that height. Consequently, when pumice of the two fine grades was placed in bags with a height of $8 \mathrm{~cm}$, the actual air content at container capacity was only $6.3 \%$ (Table 2 ). In contrast, the placement of the two fine pumice grades ( 0 to 2 and 0 to $5 \mathrm{~mm}$ ) in pots with a height of $17 \mathrm{~cm}$ enhanced their actual air content at container capacity to $10.7 \%$ and $11.2 \%$, respectively.

The yield reduction observed in all trials when the plants were cultivated in coarse pumice (4 to $8 \mathrm{~mm}$ to over $90 \%$ of the total weight), which was more profound when the substrate was placed in pots, presumably resulted from limited water supply. Indeed, the EAW in the 5- to 8- $\mathrm{mm}$ pumice grade hardly exceeded $1 \%$. Furthermore, as indicated by the corresponding moisture retention curve, the level of $\theta$ drops steeply as the suction in 4 to $8 \mathrm{~mm}$ pumice increases. As a consequence, the total water content drops to relatively low levels even at container capacity as the height of the container used to accommodate the substrate increases (Milks et al., 1989b). Indeed, as shown in Table 2, the actual water content of the coarsest pumice grade at container capacity was $30.6 \%$ in the bags, but decreased to $26.8 \%$ in the pots used for gypsophila, cucumber, and lettuce (17 cm in height) and $25.5 \%$ in those used for roses ( $24 \mathrm{~cm}$ in height); these values approach the residual water content (20.33, as shown in Fig. 2). The EAW in the 0 - to 8 -mm pumice grade was also low (less than 5\%). Hence, the yield reduction observed in gypsophila and cucumber plants grown in pots filled with 0 to $8 \mathrm{~mm}$ pumice when compared with that obtained with the two finer grades is also ascribed to limited water supply. 


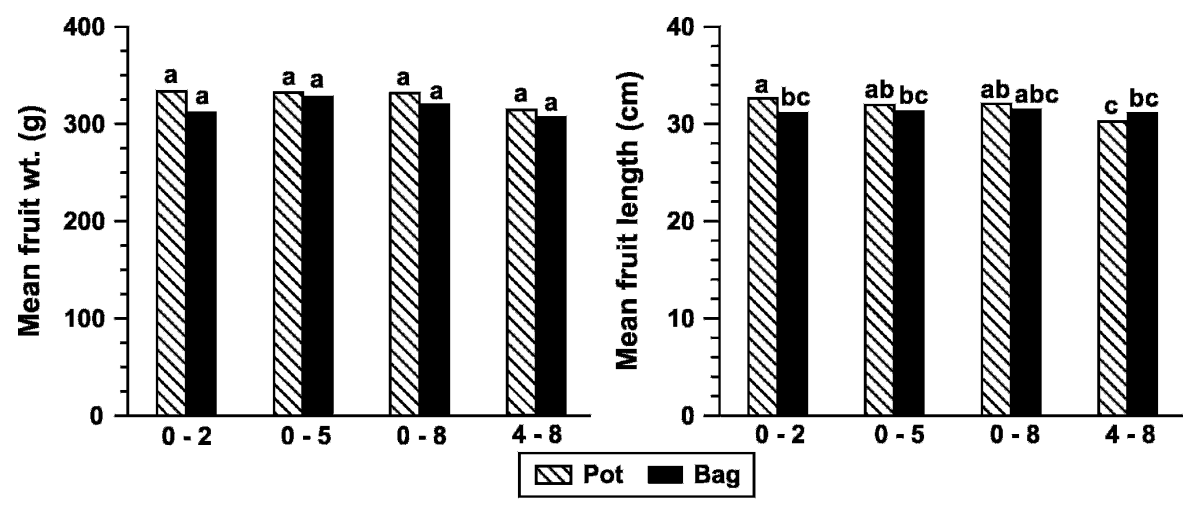

increases (Raviv et al., 1999). Hence, the steep suppression of $\theta$ within the suction range corresponding to the height of the pots in the two coarser pumice types (Fig. 2) presumably restricted the actual availability of water not only because of a lower EAW but also because of limitations in hydraulic conductivity, despite the application of a frequent irrigation schedule aimed at maintaining $\theta$ close to container capacity.

The poor response of roses to differences in particle size and substrate container may be the result of a high adaptability of this plant to a wide range of root aeration regimes as reported by Seeley (1987). However, the good

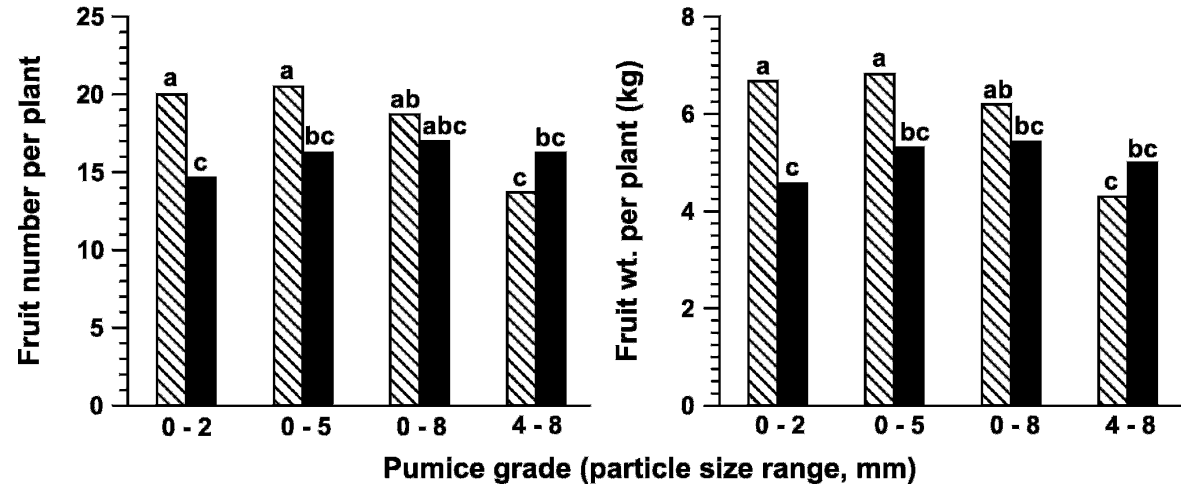

Fig. 5. Effects of particle size of pumice and cultivation method (placement of the growing media in pots or bags) on the total fruit yield and fruit size of cucumber. Values are means of three measurements. In each graph, bars denoted by the same letter do not differ significantly at $P \leq 0.05$ according to Duncan's multiple range test.

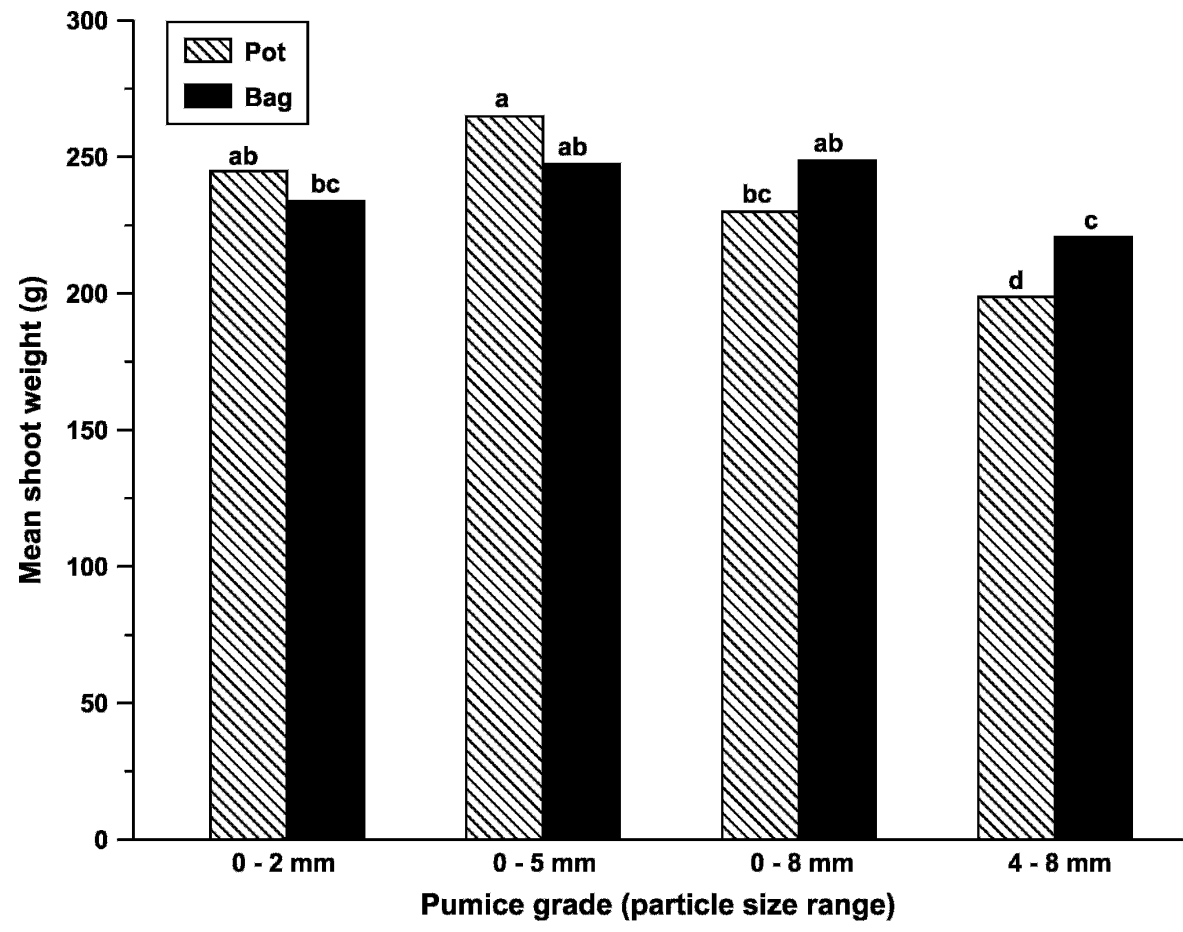

Fig. 6. Effects of particle size of pumice and cultivation method (placement of the growing media in pots or bags) on the mean fresh vegetative weight of lettuce harvested at commercial maturity. Values are means of three measurements. Bars denoted by the same letter do not differ significantly at $P \leq 0.05$ according to Duncan's multiple range test.

As pointed out by Raviv et al. (1999, 2002), the water availability in soilless media is restricted much more by the suppression of the unsaturated hydraulic conductivity as $\theta$

drops below saturation than by water limitations imposed by the level of EAW. The unsaturated hydraulic conductivity drops dramatically as the suction of the media performance of roses grown on fine pumice, even when the latter was placed in bags, may be partly the result of the enhanced height of the substrate in the bags used in the rose experiment $(12 \mathrm{~cm})$. Nevertheless, the cultivation of rose in pots containing coarse pumice ( 4 to $8 \mathrm{~mm}$ to over $90 \%$ of the total weight) markedly suppressed the number of flowers per plant, indicating that the production of rose flowers may be affected by reduced water availability. Our results are in agreement with those reported in a previous paper (Raviv et al., 1999) for roses grown on a coarse type of pumice similar to the 4- to 8-mm pumice grade used here. Plaut et al. (1973) also reported reductions in the number and length of rose flowers under water stress conditions.

Lettuce responded less sensitively than gypsophila and cucumber to differences in the particle size of pumice and the soilless cultivation method (pot or bag), presumably as a result of its adaptability to a rather wide range of air and water regimes in the roo zone (Majmudar and Hudson, 1957; Sammis et al., 1988). Nevertheless, the significantly lower mean fresh weight of plants cultivated on the coarsest pumice grade, especially when placed in pots, points to an effect associated with restricted water availability. These results indicate that lettuce may profit from an optimization of the water availability in the root zone, in agreement with the findings of Sutton and Merit (1993).

In crops grown in horticultural substrates, as a result of the limited volume of the latter, the frequency of irrigation should be high so as to maintain the moisture content in the root zone close to container capacity (Raviv et al., 1999, 2002; Sonneveld, 1995). Hence, in our experiments, a high irrigation frequency was applied, aimed at maintaining a target drainage percentage of $40 \%$ to $50 \%$ in all types of pumice, which is a standard practice in substrate-grown systems when the effluents are collected and recycled. Our results revealed that some combinations of pumice grades and container heights were unfavorable as a result of either poor aeration or poor water availability when a standard irrigation schedule was applied. Presumably, the application of a specialized irrigation schedule in such cases may mitigate problems relating to poor aeration or limited water availability. However, to test this hypothesis and to determine optimal irrigation strategies for each of these combinations of pumice grades and container 
heights, research involving different levels of irrigation frequency is needed.

In conclusion, the performance of plants grown on pumice is markedly influenced by the size fraction distribution of its particles, which affects the hydraulic properties of the media and, hence, the air and water balance in the root environment. Fine grades of pumice perform better when placed in pots, whereas the cultivation of many greenhouse plants on pumice placed in bags requires the use of coarser grades ( 0 to $8 \mathrm{~mm})$. Overall, fine grades of pumice ( 0 to $2 \mathrm{~mm}$ ) are characterized by relatively low levels of airfilled porosity, which may restrict plant growth and yield as a result of poor root aeration when the media are placed in bags or other containers with a limited height. In contrast, coarse pumice grades (4 to $8 \mathrm{~mm}$ ) are characterized by a steep drop of their water content $(\theta)$ as the media suction increases only a few centimeters above zero. This drop of $\theta$ indicates that the ability of coarse pumice grades to retain water decreases rapidly with increasing height and hence the overall water content, and presumably the hydraulic conductivity, of such pumice types are also suppressed as the height rises. As a result, the water availability may be insufficient when plants are grown on coarse pumice fractions, especially if the latter are relatively deep like in the pots here. Overall, cucumber, and especially gypsophila, perform poorly when grown on fine pumice fractions placed in shallow bags, obviously as a result of a high susceptibility to limited oxygen supply. In contrast, lettuce and especially roses proved to be more tolerant to variations in the air to water balance in the root zone originating from differences in the physical properties of the growth medium.

\section{Literature Cited}

Allaire, S.E., J. Caron, I. Duchesne, L.-E. Parent, and J.-A. Rioux. 1996. Air-filled porosity, gas relative diffusivity, and turtuosity: Indices of Prunus $\times$ cistena sp. grown in peat substrates. J. Amer. Soc. Hort. Sci. 121: 236-242.

Armitage, A.M. 1993. Specialty cut flowers. Varsity Press/Timber Press, Portland, OR.

Boertje, G.A. 1995. Chemical and physical characteristics of pumice as a growing medium. Acta Hort. 401:85-87.
Bunt, A.C. 1988. Media and mixes for containergrown plants. Unwin Hayman, London.

Challinor, P.F. 1996. The use of pumice in horticulture, p. 101-104. In: Proc., 5th Internat. Congr. Soilless Culture. ISOSC, Wageningen, The Netherlands.

Da Silva, F.F., R. Wallach, and Y. Chen. 1993. Hydraulic properties of sphagnum peat moss and tuff (scoria) and their potential effects on water availability. Plant Soil 154:119-126.

De Kreij, C., W. Voogt, and R. Baas. 1999. Nutrient solutions and water quality for soilless cultures. Research Station for Floriculture and Glasshouse Vegetables (PBG), Naaldwijk, The Netherlands, Brochure 196

Drsal, M.S., W.C. Fonteno, and D.K. Cassel. 1999. Pore fraction analysis: A new tool in substrate analysis. Acta Hort. 481:43-54.

Fonteno, W.C. 1996. Growing media: Types and physical/chemical properties, p. 93-122. In: D.W. Reed (ed.). Water, media, and nutrition for greenhouse crops. Ball Publishing, Batavia, IL.

Gislerød, H.R. and R.J. Kempton. 1983. The oxygen content of flowing nutrient solutions used for cucumber and tomato culture. Sci. Hort. 23-33.

Gizas, G., D. Savvas, and I. Mitsios. 1999. Availability of macrocations in perlite and pumice as influenced by the application of nutrient solutions having different cation concentration ratios. Acta Hort. 548:277-284.

Gunnlaugsson, B. and S. Adelsteinsson. 1995. Pumice as environment-friendly substrate; a comparison with rockwool. Acta Hort. 401:131-136.

Hanan, J.J., C. Olympios, and C. Pittas. 1981. Bulk density, porosity, percolation and salinity control in shallow, freely draining potting soils. J. Amer. Soc. Hort. Sci. 106:742-746.

Klieber, A., W.C. Lin, P.A. Jolliffe, and J.W. Hall 1993. Training systems affect canopy light exposure and shelf life of long English cucumber. J. Amer. Soc. Hort. Sci. 118:786-790.

Majmudar, A.M. and J.P. Hudson. 1957. The effects of different water regimes on the growth of plants under glass. II. Experiments with lettuces (Lactuca sativa Linn.). J. Hort. Sci. 32:201-213.

Maloupa, E. 2002. Hydroponic systems, p. 143178. In: Savvas, D. and H.C. Passam (eds.). Hydroponic production of vegetables and ornamentals. Embryo Publications, Athens, Greece.

Maloupa, E., A. Abou-Hadid, M. Prasad, and C. Kavafakis. 2001. Response of cucumber and tomato plants to different substrates mixtures of pumice in substrate culture. Acta Hort. 559: 593-600.

Milks, R.R., W.C. Fonteno, and R.A. Larson. 1989a. Hydrology of horticultural substrates: I. Mathematical models for moisture characteristics of horticultural container media. J. Amer. Soc. Hort. Sci. 114:48-52.
Milks, R.R., W.C. Fonteno, and R.A. Larson. 1989b. Hydrology of horticultural substrates: III. Predicted air and water content of limitedvolume plug cells. J. Amer. Soc. Hort. Sci. 114:57-61.

Plaut, Z., N. Zieslin, and I. Arnon. 1973. The influence of moisture regime on greenhouse rose production in various growth media. Sci. Hort. 1:239-250.

Raviv, M., R. Wallach, A. Silber, and A. Bar-Tal. 2002. Substrates and their analysis, p. 25-101. In: Savvas, D. and H.C. Passam (eds.). Hydroponic production of vegetables and ornamentals. Embryo Publications, Athens, Greece.

Raviv, M., R. Wallach, A. Silber, Sh. Medina, and A. Krasnovsky. 1999. The effect of hydraulic characteristics of volcanic materials on yield of roses grown in soilless culture. J. Amer. Soc. Hort. Sci. 124:205-209.

Sammis, T.W., B.A. Kratky, and I.P. Wu. 1988. Effects of limited irrigation methods on lettuce and Chinese cabbage yields. Irrig. Sci. 9:187198.

Savvas, D. 2001. Nutritional management of gerbera (Gerbera jamesoni) grown in a closed soilless culture system. Acta Hort. 554:175182.

Savvas, D. and G. Manos. 1999. Automated composition control of nutrient solution in closed soilless culture systems. J. Agr. Eng. Res. 73:29-33.

Seeley, J.G. 1987. Soil aeration, p. 39-42. In: Langhans, R.W. (ed.). Roses. A manual of greenhouse rose production. Roses Incorporated, Haslett, MI.

Sonneveld, C. 1995. Fertigation in the greenhouse industry, p. 121-140. In: Proceedings of the Dahlia Greidinger International Symposium on Fertigation. Technion-Israel Institute of Technology, Haifa, Israel.

Sutton, B.G. and N. Merit. 1993. Maintenance of lettuce root zone at field capacity gives best yields with drip irrigation. Sci. Hort. 56:1-11.

Van Genuchten, M.T. 1980. A closed-form equation for predicting the hydraulic conductivity of unsaturated soils. Soil Sci. Soc. Amer. J. 49:12-19.

Van Genuchten, M.T. and D.R. Nielson. 1985. On describing and predicting the hydraulic properties of unsaturated soils. Ann. Geophys. 3:615-628.

Van Os, E.A., T.H. Gieling, and M.N.A. Ruijs. 2002. Equipment for hydroponic installations, p. 103-141. In: Savvas, D. and H.C. Passam (eds.). Hydroponic production of vegetables and ornamentals. Embryo Publications, Athens, Greece.

Wallach, R., F.F. da Silva, and Y. Chen. 1992. Hydraulic characteristics of tuff (Scoria) used as a container medium. J. Amer. Soc. Hort. Sci. 117:415-422. 